\title{
Research Teaching Reform of Foreign Language based on Computer Network
}

\author{
Huimin Sun ${ }^{1, a}$ \\ ${ }^{1}$ Foreign Languages' College, Beihua University, 132013, Jilin City, China. \\ aHuimin-sun@126.com
}

Keywords: Teaching reform, Foreign Language education, computer network

\begin{abstract}
With computer and network enters foreign language teaching, changes would take place undoubtedly in many aspects, such as teaching information delivery, integration of contents into learning activities, teaching process, teaching structure, etc. Particularly in present college English teaching reform. This paper is written to argue and explore English teaching reform based on computer and network, focusing on some major problems in the integration process and trying to elaborate some issues concerning Computer and Classroom-based college English teaching model.
\end{abstract}

\section{Introduction}

20th century, the rapid development of science and technology to promote comprehensive human society entered the information age, and to a computer network as the core of modern information technology has become a 21 st century basic human living environment. It should be said that with the maturing of information technology, computer network at an unprecedented speed into modern life and more present on changing people's way of life. Therefore, we should seize the opportunity, at the height of the information society, with a new perspective and vision to re-examine our education, and use a computer network as the core of modern information technology system and the reform of education and teaching mode. This study will be the rapid development of information technology and English teaching reform, this paper discusses the integration of computer networks and foreign language teaching, focusing on teaching mode of computer network integration in the process of problems and difficulties, in order to explore the corresponding countermeasures and methods.

The main significance of this study is to promote the role of information technology in today's education immeasurable. But to make IT really can promote foreign language education, development of education, information technology and foreign language teaching must fully organic integration because the integration of information technology and teaching, especially in the integration of foreign language teaching has very important significance: it can 1) change people's learning beliefs; 2) indicate the direction of future development of education.

The rapid integration of computer and network technology and curriculum is profoundly affected and changed the ecology of various disciplines, foreshadowed the future development of the subject. We can say that the main way for future learning is no longer just rely on books or teachers teach, facing vast ocean of knowledge and constantly updated network information, teachers originally fixed, fixed classes, fixed content, fixed process, fixed standard unidirectional acceptance style of learning will be broken. Instead, a new learning process, in this learning process, students with computers and networks, and other multimedia devices as an intermediary in the independent choice, reasonably acceptable, scientific processing, timely feedback of information transmission in the complete full ease personalized, discovery learning. This discovery will change the way learning classroom-centered, teacher-centered and textbook-centered learning to accept the pattern, is more independent learning, cooperative learning and inquiry-based learning and discovery learning pattern appears. Clearly, the development of such changes in the pattern of learning and information technology has a direct relationship.

Experts agree that information technology is the materialization of cooperative use of technology and intelligent form of technology, with intelligent, digital, networked, personalized, 
multimedia-oriented features. With the extensive application of information technology, knowledge-intensive, information technology product life cycles to accelerate the emergence of the phenomenon. Meanwhile, the emerging science in large numbers, the total amount of the rapid expansion of knowledge, knowledge updating process is unprecedented accelerated emergence of the "knowledge explosion" phenomenon. According to UNESCO statistics, humans nearly 30 years of accumulated scientific knowledge accounted for $90 \%$ of the total amount of scientific knowledge accumulated in the history, while in the previous thousands of years of accumulated scientific knowledge only $10 \%$. British technology experts predict measurement results Martin also shows the same trend: in the 19th century, human knowledge is doubling every 50 years, in the early 20th century is doubling every 10 years, 70 years is doubling every five years, the past 10 years, approximately doubling every three years. It is predicted that around the year 2050, humans are now state of knowledge, the knowledge will be only $1 \%$ of the total, that is to say, to the information after the human society, will create more than 99 per cent of new knowledge.

\section{Information and knowledge system}

Visible, if product information and knowledge as frequent replacement. This extremely rapid expansion of knowledge and update our curriculum inevitably caught in an awkward position. On the one hand a lot of new knowledge content needs to be added to the curriculum, on the other hand our course content too much too difficult burden on students is increasing. As we all know, the expanded curriculum time is limited, in this case, we cannot extend indefinitely the time learner, but the rapid development of modern science and technology, a sharp increase in knowledge and information, so that we had to face the reality challenge. So how do you find a way to deal with it? The fundamental way out is to change, to change the learning process is a simple inherited the traditional view. Courses should be taught some basic knowledge, focus on innovation and the ability to adapt to the culture of the educated, the most important thing is learning to learn, with a capacity for lifelong learning, that is, the ability to self-renewal of knowledge structure. For the study of knowledge, the emphasis is to equip students with knowledge of the means, methods that learn to discover their own knowledge of their own to acquire and update their knowledge, not just limited to the study of knowledge itself.

Due to the rapid growth of the information age of knowledge, as if like a traditional education, only emphasized learning and mastering knowledge itself, then learned most of them will soon become obsolete, unable to adapt to the needs of modern social development, and only enable students to learn knowledge, that method of learning to learn, in order to enter in the future society, capable of self-renewal of knowledge structure, continue to learn all kinds of new knowledge and new skills needed for the work through self-study. In general, traditional learning, usually maintaining learning and accepting learning, information and learning is an innovative learning and constructive learning. Maintenance learning is an inherited learning, innovative learning deal with "learn" and relationships "Learn"; receptive learning is a teacher-centered learning, students are taught the knowledge of who and constructive learning is student-centered learning, emphasizes the learner is active construction of knowledge. Learning in the Information Age is maintained from traditional learning to transform innovative learning, learning from receptive to constructive learning. To achieve this goal, computer networks and curriculum and teaching must be fully integrated mode, because it indicates the future direction of development of education.

Once people learn the concept has been changed, the future of education will naturally have a new outlook. In fact, the world of education in the future when they advocated as an educational information network technology, teaching reform an important part. For example: the United States early in 1996 published "Let the American students to prepare for the 21st Century: Meeting the Challenges of technological capabilities," the National Information Technology Education Program. The prospect of such a plan in the future: through effective use of information technology in primary and secondary education network, and help the next generation get a better education prepare students to meet the new needs of the global economic development. Thereafter, the US Department of 
Education, in consultation with the community and experts, the national information technology education program has been modified, the proposed five objectives: 1) All teachers and students are required to use the information network technology; 2) All teachers should the use of technology to help students achieve high academic standards; 3) All students should have the IT knowledge and skills; 4) through research and evaluation, and promote the next generation of technology in teaching; 5) through digitized content reform of teaching and networking applications. The traditional forms of teaching will be difficult to adapt to the needs of the times, we must have a breakthrough change.

\section{Information network technology to revolutionize the educational system and teaching mode}

The EU issued a "Learning in the Information Society: European Education Innovation Action Plan", Singapore and Malaysia have also launched a national education information program. My Government also attached considerable importance to the work of education information and launched a series of policies and measures to promote information and education reform. In 2000 the Ministry of Education held a national information technology education in primary and secondary schools working meeting and make a decision: in 2001 only use 5-10 years, the national primary and secondary education basically universal information technology, information technology to stimulate the modernization of education, strive to achieve leapfrog development of basic education. It is because of this countries attached considerable importance to the traditional education system and teaching model reform of the world are forming a new educational development trend. Therefore, in many such number of classroom lectures, teachers cannot take into account the various levels of students, it is bound to reduce the effectiveness and efficiency of teaching, thus affecting the overall quality of teaching.

In China, the use of information network technology to the traditional education system and reform the teaching mode begins with our first foreign language teaching. As mentioned earlier, the 21st century, information technology is actually full century of development, especially the development of computer and network technology has greatly expanded the boundaries of time and space education, an unprecedented increase people's interest in learning, efficiency and initiative. On foreign language teaching in the Information Age, the traditional forms of teaching will be difficult to adapt to the needs of the times, we must have a breakthrough change. Change is not only significant changes in forms of teaching and learning of this teaching, more importantly, will have a profound impact on theories, concepts, models, content and methods of foreign language teaching, foreign language teaching to impart a more profound new meaning.

\section{Traditional teaching model is being challenged}

In China's college English classroom mainly teacher-centered, teacher lectures, the fine solution grammar and vocabulary, practice organization, and check your answers. For decades, even though this "chalk and talk 'teaching methods, ignoring the initiative of the competent learners, but our teachers rely on personal charisma and teaching experience teaching in small classes and individualized way, and indeed many Western trained personnel. However, with the development of the times, especially in the 21st century, before our teaching environment and for half a century, and that was the first to develop a "College English Syllabus" Twenty years ago have taken place great changes, this teaching model is bound to be an unprecedented challenge, which is mainly manifested in the following aspects:

1. The traditional model cannot effectively develop students' English language proficiency. As we all know, the characteristics of the traditional teaching model is that teacher-centered classroom instruction, "the textbook ++ blackboard chalk" as a tool to help learners acquire knowledge and the accumulation of language (mainly vocabulary and grammar) in the limited classroom time purpose. This teaching mode structuralism grammar-translation method, based on the input language in the form of a stage to the learner through the core textbook succinctly and Pham Van (usually use the vocabulary and grammar rules, etc.). Learners' solution through the fine teachers and their own drill 
to form the habit of correct language (language habits) behavior and language (linguistic performance). This is the traditional mode of teaching our unique "intensive farming peruse" type, so called "Intensive Reading."

2. Traditional teaching model to make the teaching quality. The major decline in the quality of teaching and university enrolment pressure, since the class size so that the original university enrolments expanded dramatically. According to Cai Jigang survey, just reopening, a relatively small number of university students, English learning classes generally about 35 people until 1998 years ago, the English students in the class universities in general are stable at about 40 people. Such class size, teachers can still use some time to organize some oral activity or group discussions. However, since 1998, China's university enrolments allows enrolments of $8 \%$ annual growth rate in 2004 reached 420 million, four times as much as in 1998. Thus originally shortage of teachers, it is stretched, class sizes will be expanded only. As University of Posts and more than a hundred English in Big reached 35, including the implementation of the Integrated Course closed three classes, the number of close to 150 people, so there are 27 classes, 78\%. Meanwhile, Li Aihua for efficient sample survey in Jiangsu, Shanghai and other cities found that most colleges and universities college English class in an average number of 70 people. Class size rapid expansion, is bound to make the traditional "intensive reading" Teaching Mode difficult to adapt, leading to a series of problems:

First, the class size, the more, the less interaction of teachers and students. Imagine a class 45 minutes per person to say a few turns, the time is almost finished soon. This shows that class size is too large, their students the opportunity to practice many relatively reduced. Nankai University in their teacher survey found that 85 percent of college English teachers to students to hear the reasons blamed too poor class size (Chuang Chi-like, etc. 2004). Secondly, Ambassador teaching class size reduced efficiency, but also increase the difficulty of classroom management. About 80 people in a classroom, the teacher is almost impossible to control the level differences between students that they can grasp the scope, the teacher can do is to follow the pre-designed lesson plans teaching, "and the larger the class size, the more the level of student uneven, poor students because the teacher cannot keep up the rhythm, do not understand and simply absent; higher levels of students are too slow and too class do their thing." Therefore, in many such number of classroom lectures, teachers cannot take into account the various levels of students, it is bound to reduce the effectiveness and efficiency of teaching, thus affecting the overall quality of teaching.

3. The traditional model cannot adapt to changes in the social and linguistic environment. It should be said by the traditional teaching mode in class size constraints, but also influenced by other social and environmental factors. First, the environment and the means of learning is changing. In the past few decades, college English classroom teaching to carry around textbooks, occasionally listen to some recordings. Now, with the rapid development of information technology, students can access to knowledge and information becomes rich, foreign language learning is no longer satisfied with the students around the turn of the traditional textbook approach. According to the survey of Shanghai Jiaotong University, $83 \%$ of students prefer to watch television, video and other learning English, students have tended to abandon the textbook to learn English alone mode, shift to from a variety of media and channels accept input. The traditional forms of teaching will be difficult to adapt to the needs of the times, we must have a breakthrough change. Visible, the traditional teaching model under the impact of multimedia computers, networks, etc., is bound to lose its original position and advantages. Second, changes in student motivation. The main purpose of the last students to learn English is to pass the exam, you can get a diploma, so learning quite passive, just follow the textbook to learn enough. Now, the situation is different, not only for students to learn English a diploma, they have for future employment, study abroad, graduate education and other efforts to increase college English, and to learn to become more active, and learning content made more personal, in particular, is the integrated use of language, the more is required to have improved significantly. These are the traditional mode of teaching challenge, but teachers tell students to listen to the pattern simply cannot meet the needs of individual students in the classroom. Thus, the traditional mode of teaching is 
difficult to cope with these changes. To change this situation, to meet the new requirements of society and students, teaching mode change is imperative.

\section{Summary}

It can be said of this thesis and the integration of foreign language teaching computer networks are full and comprehensive research and exploration, not only discussed the development and college English teaching reform program, but also analyzed and discussed the development and function of the application of computer technology proposed some constructive innovative ideas, specifically summarized as follows:

1. After the computer network and Foreign Language Teaching Integration, constitute the paradigm curriculum changes, which constitutes a paradigm shift from the traditional " $2+1$ " model (theory, method + curriculum or textbooks) " $3+1 "$ model (theory, methodology, technology + curriculum or textbooks), namely teaching theory, teaching methods, information technology (educational technology) embodied in the curriculum or teaching materials. Course paradigm change constitutes one of the primary characteristics in a computer network environment targeted foreign language courses.

2. After the computer network and the integration of foreign language teaching, computer-assisted starting position toward the teaching front, that the status of the computer in the course has been a fundamental change, has become an integral part of the course, become the teaching a feature.

3. After the computer network and the integration of foreign language teaching, teaching model has changed the traditional teacher-centered model is broken. Not only emphasized the need for foreign language teaching student-centered teaching mode, and more emphasis on the use of modern information technology to promote information technology teaching model independent learning.

4. After the computer network and the integration of foreign language teaching, teaching structure has changed, it has become three-dimensional, multimedia-oriented materials. However, the current status quo, the three-dimensional materials are embodied in the concept of teaching physical constitution, especially online teaching content paper textbooks has become a replica of effective teaching should constitute an extension of the paper web content textbooks rather than a replica. In view of this, this paper presents the development of the fifth generation idea of college English textbooks.

5. After the computer network and the integration of foreign language teaching, teaching elements of change, many traditional elements (such as teaching material, content, methods, etc.) are the new features (such as multi-media, web content, technical methods, etc.) are replaced. Changes feature naturally breaking the balance of the traditional foreign language teaching system environment. Imbalance teaching environment has led many imbalances occur. FLT original ecological balance is broken, the education system is not natural, harmonious, efficient operation. Visible, to make computer networks and our foreign language teaching naturally integrated, making the teaching system to maintain dynamic harmony, it should re-examine the perspective of ecology to it. Operation FLT ecosystems must focus on this two principles: First, stable teaching structure, compatible teaching elements; second is to restrict the teaching operation, promote individual development. From an ecological perspective, compatible, dynamic, healthy harmony is the essence of teaching ecosystems.

\section{Acknowledgements:}

Education research Beihua University: "English curriculum and teaching theory" classroom teaching and online teaching and practice of combining Dynamic Model

\section{References}

1. Sun Ruoting of market-oriented operation characteristic school English training institutions in China SCHOOL EDUCATION (theory), 2007 (4): 108 
2. Li Haiyan. On the Problems and Reform of College English Teaching. Huazhong Normal University, 2009 (6)

3. Liu spruce. Teacher-student interaction in the power relationship [J]. Hunan Normal Science Education, 2008 (1)

4. Qin show white people adhere to this teaching theory, the full implementation of the "College English Curriculum Requirements" - On the "New Century College English textbook series", "Integrated Course" of compiling ideas, Foreign Language Education, 2008 (5)

5. ROCKETS. How to improve the ability to listen to English news as soon as possible. Foreign Language Education, 2000 (2)

6. Yuhong Min. Value of the return, embrace tomorrow Zhongguancun 2010 (11) 90

7. Study on Yang. New Oriental English Teaching, Hunan Normal University, 20104

8. Yu-fang, rather cool. College English Teachers' Quality in order to promote English teaching reform, education and occupation, 2009 (27)

9. Yuan Wen study teachers 'professional development and planning of a teachers' professional development mechanism. East China Normal University, 2008 (3). 